\title{
MULTIFUNCTIONALIZATION OF A CELLULOSIC MATERIAL BY MEANS OF A MULTIPLE-STEP COATING PROCESS APPLYING ORGANOTRIALKOXYSILANES
}

\author{
CHRISTIAN SCHRAMM and DORIAN RHOMBERG \\ Research Institute of Textile Chemistry and Textile Physics, University Innsbruck, \\ Höchsterstrasse 73, A-6850 Dornbirn, Austria \\ 区 Corresponding author: Ch. Schramm, christian.schramm@uibk.ac.at
}

Received May 20, 2020

The sol-gel process is an excellent process for coating various substrates and thus imparting new functionalities to the treated material. Cotton fabrics were finished with various silicon alkoxides: tetraethoxysilane, (3triethoxysilylpropyl)succinic acid anhydride, and (3-glycidyloxy)propyltrimethoxysilane in a one-, two-, and three-step process, applying the pad-dry-cure method. The physico-mechanical parameters: dry crease recovery angle, tensile strength, flexural rigidity, air permeability, abrasion resistance, whiteness index (WI), and water vapor permeability of the as-prepared cotton samples were evaluated. In addition, the coated samples were analyzed by means of Fourier transform-infrared/attenuated reflection spectroscopy, thermal gravimetric analysis, and 3D laser confocal microscopy. To study the wettability, selected alkoxysilane-treated specimens were coated with octyltriethoxysilane. The impregnation with titanium tetraisopropoxide significantly increased the ultraviolet protection factor. The findings make evident that the wrinkle resistance could be improved.

Keywords: polysaccharide, cotton, surface modification, sol-gel process, alkoxysilanes

\section{INTRODUCTION}

Cotton is a natural fiber and an important resource for the apparel industry. The cotton fiber mainly consists of the natural raw material cellulose $(>95 \%))^{1,2}$ It has good strength and provides excellent comfort due to its ability to hold and release moisture. However, cotton material suffers from a few disadvantages, such as the tendency to wrinkle, poor dimension stability and high flammability. Consequently, after the pretreatment and coloration stage, cotton fabrics are subjected to various finishing processes to impart the final, customer-tailored properties to the textile material. These finishing processes can be conducted either under dry conditions, such as plasma treatment, ${ }^{3,4}$ or under wet conditions. ${ }^{5}$

During the last two decades, the sol-gel process that takes place in an aqueous medium has attracted increasing interest in the modification of textile-based materials to convey novel functionalities to cotton fabrics. ${ }^{6}$ The solgel technique is a synthetic route that involves acidic- or alkaline-catalyzed hydrolysis and a subsequent low-temperature condensation reaction of metal or semimetal alkoxides, the socalled precursors, in an appropriate solvent. ${ }^{7,8}$ Various inorganic or organic substances can be incorporated into these precursor-containing nanosol solutions, which are applied to the textile surface by the pad-dry-cure method, thus making possible the formation of organic-inorganic hybrids. ${ }^{9}$

Multiple-step processes also enable the production of multi-functional textile surfaces. Colleoni et al. applied a multi-layer approach using tetraethoxysilane as precursor. ${ }^{10}$ Cotton material was modified with layers consisting of $\mathrm{SiO}_{2} / \mathrm{TiO}_{2}$ at low temperature. ${ }^{11}$ Cotton fabrics were treated in a two-step process, applying $\mathrm{Zn}$ (II)acetate and 1,4-benzenedicarboxylic acid to impart antibacterial properties. ${ }^{12}$

Most of the sol-gel based modification studies were focused on the improvement of the physicomechanical functions, such as crease resistance, ${ }^{13-}$ 16 flame retardancy, ${ }^{17-19}$ UV protection, ${ }^{20-22}$ 


\section{CHRISTIAN SCHRAMM and DORIAN RHOMBERG}

hydrophobicity, ${ }^{23-25}$ or self-cleaning. ${ }^{26-29}$ The solgel method also was applied on textiles for various medical applications, such as drug release, ${ }^{30,31}$ wound healing, ${ }^{32}$ or antimicrobial finishing. ${ }^{33-35}$ Efforts have been undertaken to produce smart textiles capable of reacting to environmental stimuli. ${ }^{36,37}$ The sol-gel method is also used to improve the wash fastness of dyed cellulose-based fabrics. ${ }^{38,39}$

The present study was undertaken with a view of investigating the feasibility of carrying out multi-functional finishing of cotton fabric by multiple treatments of the cotton samples with different alkoxysilanes.

\section{EXPERIMENTAL \\ Materials}

Tetraethoxysilane (98\%, TEOS) and ethanol (>97\%) were purchased from Fluka Chemie $\mathrm{GmbH}$, Buchs, Switzerland. (3-Triethoxysilylpropyl)succinic acid anhydride (TESP-SA, 100\%), (3glycidyloxy)propyltrimethoxysilane (100\%, GPTMS), and octyltriethoxysilane (100\%, OTEOS) were donated by Wacker Silicone, Burghausen, Germany. Titanium tetraisopropoxide (98\%, TTP) was purchased from Sigma-Aldrich, Vienna, Austria. The chemical formula of the substances can be seen in Figure 1. The chemicals were applied without further purification. Deionized water (DI) was used throughout the investigation. Desized, scoured, bleached $100 \%$ cotton fabric (weave type: plain, density warp: 52 yarn $/ \mathrm{cm}$, weft: 24 yarn $/ \mathrm{cm}$, weight: $109 \mathrm{~g} / \mathrm{m}^{2}$ ) was utilized throughout the study and is denoted as raw material (RM).<smiles>CCO[Si](OCC)(OCC)OCC</smiles>

Tetraethoxysilane TEOS<smiles>CO[Si](CCCOCC1CO1)(OC)OC</smiles>

(3-Glycidyloxypropyl)trimethoxysilane GPTMS<smiles>CCO[Si](CC)(OCC)OCC</smiles>

(3-Triethoxysilylpropyl)succinic acid anhydride TESP-SA<smiles>CCCCCCCC</smiles>

Octyltriethoxysilane OTEOS<smiles></smiles>

Titan tetraisopropoxide

TTP

Figure 1: Chemical formulae of the compounds of interest

\section{Preparation of the organotrialkoxysilane solutions}

The finishing solutions were prepared as follows: $30 \mathrm{mmol}$ of each of the alkoxysilanes (TEOS, GPTMS, TESP-SA,) were hydrolyzed in $30 \mathrm{~mL}$ DI and $5 \mathrm{~mL}$ $\mathrm{HCl}(\mathrm{c}=0.1 \mathrm{~mol} / \mathrm{L})$ at room temperature for $3 \mathrm{~h}$ under stirring in polypropylene beakers, which were sealed with a pierced parafilm (Bemis, Neenah, Wisconsin,
USA). Subsequently, the volumes of the homogenous solutions were filled up to $100 \mathrm{~mL}$ with DI. $16 \mathrm{~mL}$ (50.34 mmol) of OTEOS were dissolved in $150 \mathrm{~mL}$ of ethanol. $3 \mathrm{~mL}$ of $\mathrm{HCl}(\mathrm{c}=0.1 \mathrm{~mol} / \mathrm{L})$ were added and the solution was stirred for $3 \mathrm{~h}$ at room temperature. The titanium dioxide-nanosol solution was prepared by mixing TTP (1\%) with $100 \mathrm{~mL}$ of DI containing nitric 
acid (1\%) under vigorous stirring for $48 \mathrm{~h}$ using a magnetic stirrer. After a certain period, a transparent, yellowish solution was obtained. ${ }^{20}$

\section{Preparation of the cotton samples}

The pre-weighed cotton samples were impregnated with the corresponding alkoxide solutions, applying a two-roll laboratory padder (HVL 500 Mathis AG, Niederhasli, Switzerland; air pressure 1 bar, rotary speed $3 \mathrm{~m} / \mathrm{min}$ ). The samples were dried at $105{ }^{\circ} \mathrm{C}$ for $2 \mathrm{~min}$ in a lab dryer (LTE, W. Mathis AG,
Switzerland). The condensation reaction was conducted at $160{ }^{\circ} \mathrm{C}$ for $10 \mathrm{~min}$. The scheme of preparation is shown in Figure 2.

The as-prepared cotton specimens are coded as follows: the terms TE, GP and TS refer to the cotton samples treated with TEOS, GPTMS and TESP-SA, respectively. The coding of the multiple-treated samples is explained in terms of an example: TE-GPTS denotes the sample that was firstly treated with TEOS, subsequently with GPTMS, and finally with TESP-SA.

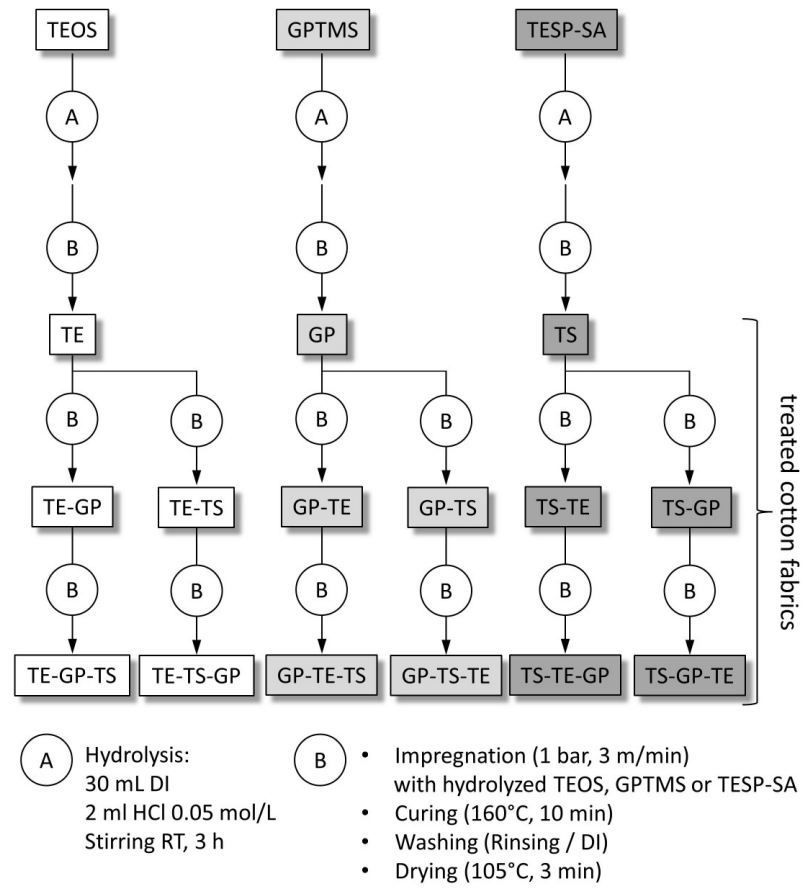

Figure 2: Modification scheme for the multiple-step preparation of the nanosol-modified cotton samples

Prior to the contact angle measurements, the cotton samples were immersed for $1 \mathrm{~h}$ into the OTEOScontaining solution, dried for $12 \mathrm{~h}$ at room temperature, and cured for $15 \mathrm{~min}$ at $150{ }^{\circ} \mathrm{C}$.

To impart UV protection properties, the cotton samples were impregnated with titanium dioxidenanosol, applying the two-roll laboratory padder, and cured for $15 \mathrm{~min}$ at $150{ }^{\circ} \mathrm{C}$.

\section{Apparatus and methods}

The add-on of the fabric weight was calculated as follows: add-on $(\%)=\left[\left(\mathrm{W}_{2}-\mathrm{W}_{1}\right) / \mathrm{W}_{1}\right] \times 100$; where $\mathrm{W}_{1}$ and $\mathrm{W}_{2}$ are the weights of the fabric specimens before and after the treatment, respectively. Dry crease recovery angle (DCRA) was measured according to ISO 2312: 10 test specimens were creased and compressed under controlled conditions of time and load. After removal of the creasing load, the angle formed between the two limbs was measured. The DCRA values render possible the evaluation of a cross- linking reaction between a crease-resistant finishing agent and the cellulosic material. Tensile strength (TS) was determined with the Material Testing System Z010 (Zwick/Roell, Ulm, Germany) according to DIN EN ISO13934. The stiffness of the fabrics was determined by means of a Taber Stiffness Tester, Model 112, New York, USA, according to ASTM D 1388-R6. The flexural rigidity was calculated as described in ASTM D 1388-R6. Abrasion tests were performed according to DIN EN ISO 12947 (Martindale method): the circular sample was mounted on a specimen holder and subjected to a defined load (12 kpa). Then, it was rubbed against a standard fabric in a translational movement. The measurement of the air permeability was conducted according to DIN EN ISO 9237 using the air permeability tester Textest FX 3030 LDM, Textest Ldt, Zurich, Switzerland. The air flux $\left(\mathrm{L} / \mathrm{dm}^{2} / \mathrm{min}\right)$ that passes through the fabric was evaluated at a pressure difference of $100 \mathrm{~Pa}$. Colorimetric data measurements were conducted with 
the Spectrophotometer CM-3610d from Konica Minolta, Japan. The color data software CM-S100w Spectra Magic NX V1.9 was used for data acquisition.

The water vapor permeability was studied gravimetrically by placing disks covered with the cellulosic specimens in a desiccator at air humidity of $100 \%$, at $23{ }^{\circ} \mathrm{C}$ for $96 \mathrm{~h}$. The WVP rate was measured gravimetrically using the water method, following ASTM E96. A plastic cup (4 $\mathrm{cm}$ diameter, $2.5 \mathrm{~cm}$ height, $25 \mathrm{~mL})$ was partially filled with DI $(11 \mathrm{~mL})$. A hole $(1.5 \mathrm{~cm}$ diameter $)$ in the lid of the cup was sealed with the circular test specimen. This cup assembly was placed in a desiccator filled with silica gel. The initial weight of the assembly was taken and it was reweighed after $96 \mathrm{~h}$.

FT-IR/ATR spectra were recorded with a Bruker Vector 22 spectrometer using a DTGS detector. The spectra were the result of 50 scans. The spectral resolution was $4 \mathrm{~cm}^{-1}$. A PIKE MIRacle TM ATR accessory, equipped with a diamond ATR crystal, was used. The surface morphology was studied by means of a 3D laser confocal microscope (Keyence VKX150, Osaka, Japan). TG measurements were conducted with the thermogravimetric analyzer TGA 2 (Mettler-Toledo GmbH, Vienna, Austria) in air, using a heating rate of $10{ }^{\circ} \mathrm{C} / \mathrm{min}$ and a scan range of $40-800$ ${ }^{\circ} \mathrm{C}$.

The contact angle values were assessed using a home-made contact angle measuring device, which consisted of a digital microscope camera (DigiMicro 2.0 Scale, Software Microcapture; dnt $\mathrm{GmbH}$, Dietzenbach, Germany). Precise contact angle measurements were conducted using the IMAGEJ software (Research Services Branch of the National Institute of Mental Health, Bethesda, MD, USA) and the plug-in Drop Analysis (Biomedical Imaging Group, Ecole Polytechnique Federale de Lausanne, Switzerland). ${ }^{40}$ The UV protection efficiencies of the treated fabrics were quantified according to the Australian/New Zealand Standard AS/NZS 4399:1999, applying a Specord 50 UV-VIS spectrophotometer, equipped with a photometer sphere (Analytik ZeissJena, Jena, Germany).

\section{RESULTS AND DISCUSSION}

Different chemical agents are applied to convey novel properties to the surface of polysaccharide-based materials. For this purpose, precursors, such as TEOS, GPTMS, and TESPSA, are subjected to acidic- or alkaline- catalyzed hydrolysis, thus forming a homogenous, aqueous nanosol solution comprising reactive silanol groups. The latter are capable of reacting with the hydroxyl groups of the polysaccharide at elevated temperatures, resulting in a permanent attachment to the textile substrate. Also, the functional groups of the organic unit of the precursors can react with the polysaccharide. Usually, the materials are chemically modified applying a single step. The present study aims to reveal the impact that is exerted on the properties of a polysaccharidebased, textile material treated by means of a threestep sol-gel process.

\section{Physico-mechanical properties of the fabrics}

In the first step of the coating process, cotton fabrics were impregnated with finishing baths containing either the hydrolyzed alkoxides TEOS, GPTMS or TESP-SA $(30 \mathrm{mmol} / 100 \mathrm{~mL})$. The asprepared specimens were coated with a second and third layer, as presented in Figure 2 . Subsequently, the physico-mechanical characteristics were evaluated. The experimental results are summarized in Table 1.

\section{Add-on}

The add-on values indicate the portion of the chemical agent that is attached to the cotton material and hence increases the weight of the fabric, which in turn influences the physicomechanical properties.

The add-on values of the first coating step can be ranked as follows: TE $<\mathrm{GP}<\mathrm{TS}$. The add-on values of TE-GP and GP-TE are about $6 \%$, those of TE-TS and TS-TE are about 9\%. The threestep coating process provides add-on values in the range from $12 \%$ to $15 \%$. These observations can be explained by the fact that the epoxide group of GPTMS is hydrolyzed to a diol functionality, whereas the anhydride unit of TESP-SA is converted into two carboxyl groups. As a result, the number of the reactive sites for the interaction with the cellulosic material is enhanced.

\section{Dry crease recovery angle measurements}

Cotton-based fabrics exhibit the undesired propensity to wrinkle. ${ }^{41}$ Therefore, cotton fabrics are finished with chemical agents resulting in a cross-linking reaction between the cellulosic chains. However, the most effective and low-cost cross-linking agent, dimethyloldihydroxyethyleneurea (DMDHEU) releases the potential human carcinogen formaldehyde. ${ }^{42}$ Various studies have been undertaken to establish non-formaldehyde, creaseresistant finishing agents. ${ }^{41,43}$ To evaluate the wrinkle-resistant properties, the DCRA values are measured. ${ }^{44}$ 
Table 1

Physico-mechanical properties of the alkoxysilane-modified cotton samples

\begin{tabular}{lcccccc}
\hline Code & $\begin{array}{c}\text { Add-on } \\
(\%)\end{array}$ & $\begin{array}{c}\text { DCRA } \\
(\mathrm{w}+\mathrm{f}) \\
(\%)\end{array}$ & $\begin{array}{c}\text { Tensile } \\
\text { strength } \\
(\%)\end{array}$ & $\begin{array}{c}\text { Flexural } \\
\text { rigidity } \\
(\%)\end{array}$ & $\begin{array}{c}\text { Air } \\
\text { permeability } \\
(\%)\end{array}$ & $\begin{array}{c}\text { WI } \\
(\%)\end{array}$ \\
\hline RM & & 100.0 & 100.0 & 100.0 & 100.0 & 100.0 \\
TE & 1.7 & 90.5 & 100.6 & 105.9 & 88.3 & 82.7 \\
TE-GP & 6.0 & 138.3 & 83.0 & 107.4 & 81.5 & 70.5 \\
TE-GP-TS & 13.3 & 151.6 & 85.5 & 154.4 & 78.8 & 64.1 \\
TE-TS & 8.5 & 136.8 & 48.0 & 108.8 & 81.5 & 63.6 \\
TE-TS-GP & 13.7 & 149.6 & 24.6 & 252.9 & 85.9 & 56.9 \\
GP & 4.2 & 129.0 & 100.2 & 101.5 & 84.6 & 74.4 \\
GP-TE & 6.0 & 147.6 & 82.8 & 139.0 & 92.2 & 63.5 \\
GP-TE-TS & 12.7 & 153.2 & 81.4 & 157.4 & 84.1 & 60.9 \\
GP-TS & 11.0 & 160.7 & 88.7 & 123.5 & 83.7 & 61.6 \\
GP-TS-TE & 12.6 & 160.9 & 73.2 & 125.7 & 81.0 & 63.2 \\
TS & 7.4 & 162.4 & 68.9 & 97.8 & 81.7 & 80.3 \\
TS-TE & 9.1 & 145.3 & 44.5 & 159.6 & 84.9 & 64.3 \\
TS-TE-GP & 14.6 & 154.8 & 40.8 & 210.3 & 91.0 & 53.9 \\
TS-GP & 11.4 & 165.7 & 72.5 & 175.7 & 84.4 & 66.4 \\
TS-GP-TE & 12.9 & 181.9 & 57.7 & 181.6 & 79.5 & 60.8 \\
\hline
\end{tabular}

The results of the DCRA measurements are shown in Table 1. TE shows poor creaseresistance, whereas the DCRA value of GP is increased. A significant improvement of the crease-resistant properties can be observed for TS. These results make evident that TESP-SA is the most effective durable press agent due to the adjacent carboxylic groups, which are capable of reacting with the hydroxyl groups of the cellulosic material. TE-TS, TE-GP, TS-TE and GP-TE also give rise to enhanced DCRA values $(136 \%$ to $148 \%$ ). However, a remarkable increase can be detected for GP-TS and TS-GP. The three-step treatment results in excellent crease recovery properties (150-182\%). The best value can be observed for TS-GP-TE. These findings confirm that the first treatment with TESP-SA results in a noteworthy improvement of the DCRA values.

\section{Tensile strength}

The DCRA values prove that the application of the alkoxysilanes causes a crosslinking reaction between the cellulose chains. Therefore, the relative movement of the chains is restricted; consequently, the distribution of the stress exerted on the individual chain cannot take place. ${ }^{45}$ This phenomenon also influences the tensile strength. The findings in Table 1 reflect that the values of the tensile strength are reduced in comparison with the sol-gel untreated RM. The highest reduction can be noticed for the cellulosic specimens that were subjected to a three-layer coating process starting with TESP-SA (40-47\%).
The cotton samples that were firstly treated with a GPTMS-containing formulation exhibit a moderate decrease. The values for TE and GP reached the same level as RM. The values are consistent with those found for the DCRA values.

\section{Flexural rigidity}

When multifunctional chemical agents react with a textile material, an increase in the weight as well as a crosslinking reaction takes place, thus causing an alteration in the stiffness properties of the textile fabric. The stiffness properties are reflected by the flexural rigidity (FR). The results are given in Table 1. TS, GP, and TE show a moderate increase in the FR values, whereas the two-step treated specimens have significantly higher values. The highest values can be observed for the samples treated with TESP-SA in the first step (TS-TE, TS-GP). The inspection of the stiffness properties of the three-step treated cellulosic fabrics makes it evident that TS-GP-TE, TS-TE-GP, and TE-TS-GP reach the highest levels. The findings are consistent with the results of the add-on measurements.

\section{Air permeability}

The air permeability is an important parameter of a woven material and it is mostly governed by the fabric's weight, thickness and porosity. ${ }^{46}$ The coating material may block the voids, which are produced between the interlaced yarns, thus influencing the air permeability. Compared to 


\section{CHRISTIAN SCHRAMM and DORIAN RHOMBERG}

RM, the air permeability of all chemically modified samples is reduced $(78.8 \%$ to $92.2 \%)$. The highest decrease in air permeability can be observed for the samples subjected to the threestep coating process (TE-GP-TS, TS-GP-TE, GPTS-TE).

\section{Abrasion resistance}

Wear and maintenance processes have a significant influence on the abrasion performance of a textile material. This is also true for the finishing agent applied to the fabric to modify the surface properties. Therefore, the abrasive properties of the prepared cotton specimens were evaluated. The abrasion characteristics of RM and the modified cotton samples are presented in Figure 3 (Fig. 3a: fabrics coated in the first step with TEOS; Fig. 3b: fabrics coated in the first step with GPTMS; Fig. 3c: fabrics coated in the first step with TESP-SA). The findings of the abrasion experiments make it evident that RM suffers the lowest loss of mass. The abrasion curves of TE, GP and TS show a moderate increase in weight loss in comparison with RM. A further enhancement of the weight loss can be observed for the two-step treated samples. A significant weight loss is detected for the threestep treated samples, especially for those which were firstly treated with TESP-SA, as can be seen in Figure 3c.

\section{Whiteness index}

The treatment of polysaccharide-based material at elevated temperatures usually results in the formation of unsaturated conjugated groups, thus causing a yellowing effect. The decomposition reactions of the cellulosic material, as well as of the finishing agents, may be due to this phenomenon. ${ }^{47}$ The results of the WI evaluation are shown in Table 1 and make it evident that, compared to RM, all nanosolmodified samples show reduced WI values. The highest decrease can be detected for TS, GP and TE. These phenomena may be due to the fact that the carboxylic groups present in TESP-SA and the vicinal diol group in GPTMS are decomposed during the heating process. A lower yellowing effect can be observed for the two-step treated and some three-step treated samples. The best protection against yellowing is given for TS-GPTE, TS-TE-GP, and TE-TS-GP.

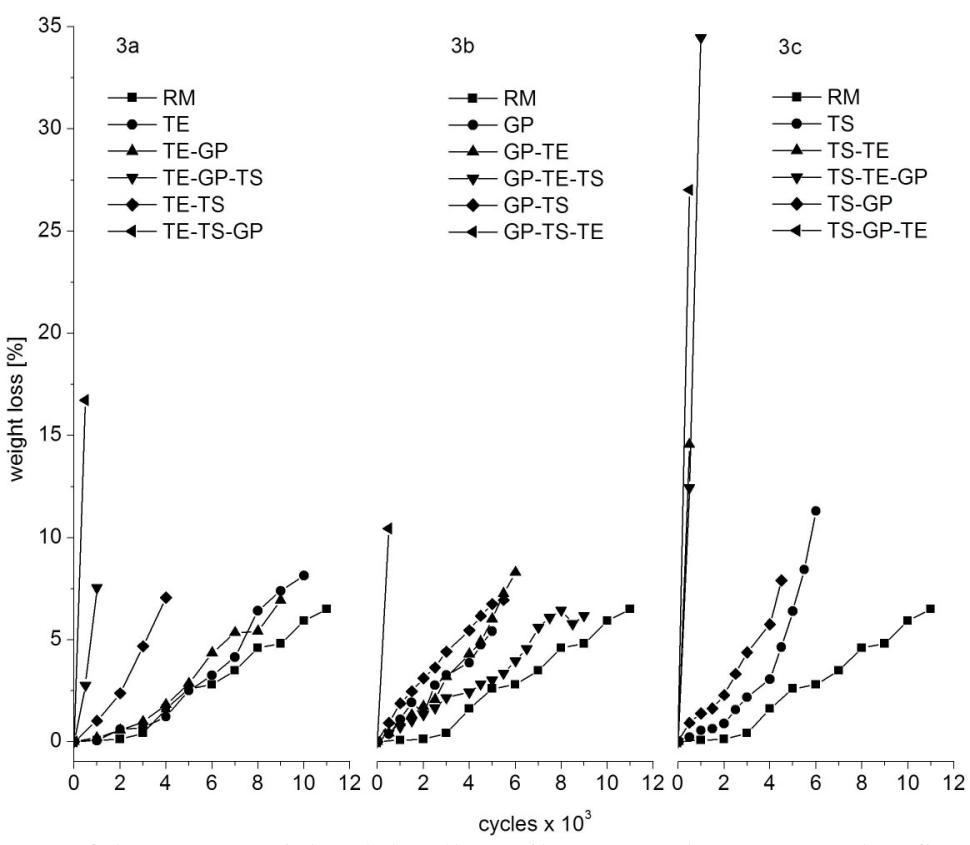

Figure 3: Abrasion curves of the raw material and the alkoxysilane-treated cotton samples: first treatment with TEOS

(3a), first treatment with GPTMS (3b), first treatment with TESP-SA (3c)

\section{Water vapor permeability}

Water vapor permeability (WVP) of fabrics plays an important role in determining the wear comfort of clothing. The fabric that comes in close contact with the skin is able to wick the sweat and transport the moisture through the layer 
to the environment, thus producing a cooling and drying effect. ${ }^{48,49}$ Therefore, it is of interest to study the interaction of the modified cotton fabrics with water vapor. For this purpose, the WVP values were measured. The findings presented in Figure 4 indicate that, compared to the raw material, the chemical modification results in enhanced WVP values. A low increase can be observed for the specimens treated with
TEOS in the first step. An additional moderate increase can be detected for the samples finished with GPTMS in the first step. The samples that were firstly treated with TESP-SA show the highest WVP values. The sequence of the treatment with various organotrialkoxysilanes seems to have no influence on the water vapor transmission.

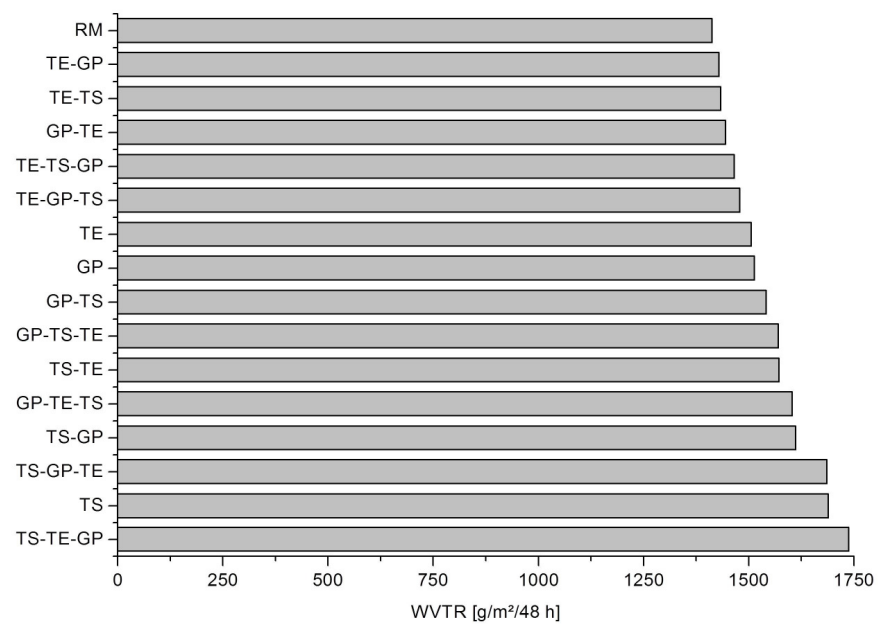

Figure 4: Water vapor permeability of the modified cotton samples after $48 \mathrm{~h}$
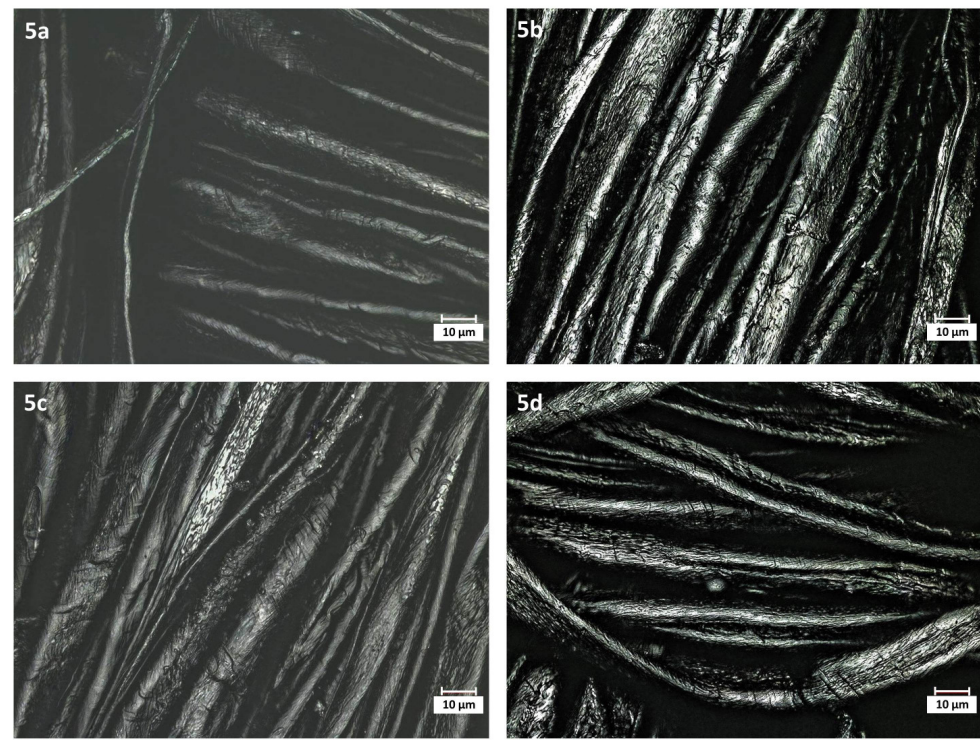

Figure 5: Confocal microscopy images of the raw material (5a), TE (5b); TE-GP (5c), and TE-GP-TS (5d)

\section{Morphology of the surface}

The surface morphology was studied by means of confocal laser microscopy. The images are presented in Figure 5: RM (Fig. 5a), TE (Fig. 5b) TE-GP (Fig. 5c) TE-GP-TS (Fig. 5d). The inspection of the figures makes it evident that no depositions can be observed on the surface of the treated fabrics. These facts indicate that no agglomeration took place in the course of the coating process. Therefore, it can be concluded 


\section{CHRISTIAN SCHRAMM and DORIAN RHOMBERG}

that the nanosol solution of the alkoxysilanes penetrated into the cotton fibers, where the functional groups of the precursor reacted with the cellulose chains.

\section{FT-IR/ATR measurements}

The FT-IR/ATR method is an excellent tool to study the functional groups present on the surface of sol-gel modified cotton material. ${ }^{50,51}$

Figure $6 a$ shows the spectrum of the sol-gel untreated RM. The group of spectra (Fig. 6b-6f) presents the spectra of the cellulosic material treated with TEOS in the first step (6b: TE; 6c: TE-GP; 6d: TE-GP-TS; 6e: TE-TS; 6f: TE-TSGP). The spectra $6 \mathrm{~g}-6 \mathrm{k}$ were obtained when GPTMS was the starting material for the modification process (6g: GP; 6h: GP-TE; 6i: GPTE-TS; 6j: GP-TS; 6k: GP-TS-TE). The application of TESP-SA as starting material provided the spectra shown in the third group of spectra 61-6p (61: TS; 6m: TS-TE; 6n: TS-TE-GP; 6o: TS-GP; 6p: TS-GP-TE).

The bands observed in region I (800-1200 $\mathrm{cm}^{-}$ $\left.{ }^{1}\right)$ are assigned to the vibration modes deriving from the siloxane group and the C-O-C unit. ${ }^{52,53}$ Thus, the weak vibration mode at $898 \mathrm{~cm}^{-1}$ can be ascribed to the asymmetric out-of-plane ring stretch of the $\beta$-glycosidic bond. The band appearing at $1028 \mathrm{~cm}^{-1}$ is due to the $\mathrm{C}-\mathrm{O}$ stretching vibration, whereas the band that is observed at $1161 \mathrm{~cm}^{-1}$ is associated with the asymmetric C-O-C vibration mode.

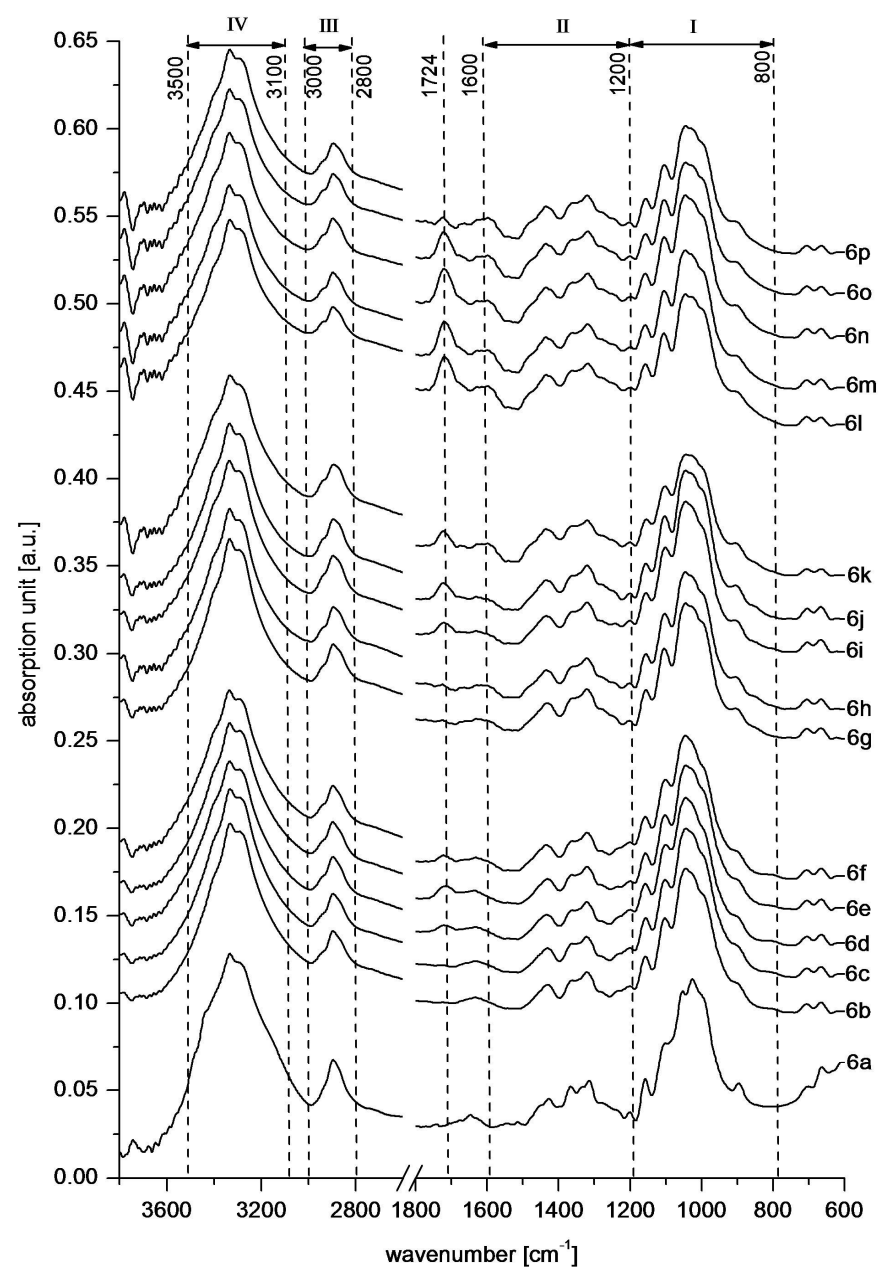

Figure 6: FT-IR spectra of 6a: RM; treated with TEOS in the first step: 6b: TE; 6c: TE-GP; 6d: TE-GP-TS; 6e: TE-TS; 6f: TE-TS-GP; treated with GPTMS in the first step: 6g: GP; 6h: GP-TE; 6i: GP-TE-TS; 6j: GP-TS; 6k: GP-TS-TE); treated with TEOS in the first step: 61: TS; 6m: TS-TE; 6n: TS-TE-GP; 6o: TS-GP; 6p: TS-GP-TE 
In region II (1200-1600 $\left.\mathrm{cm}^{-1}\right)$, the bands of the bending vibration modes of $\mathrm{C}-\mathrm{H}$ and $\mathrm{O}-\mathrm{H}$ groups are visible. The band at $1319 \mathrm{~cm}^{-1}$ can be ascribed to the $\mathrm{CH}$ wagging bands. The band at $1367 \mathrm{~cm}^{-1}$ is due to the $\mathrm{OH}$ in-plane bending and the one at $1435 \mathrm{~cm}^{-1}$ can be assigned to $\mathrm{CH}$ wagging (inplane). The band at $1640 \mathrm{~cm}^{-1}$ stems from the $\mathrm{OH}$ stretching vibration of adsorbed water.

A noteworthy aspect of the spectra is that no absorption band can be observed at $1255 \mathrm{~cm}^{-1}$, indicating that no epoxide ring is present in the cotton samples that were treated with GPTMScontaining finishing baths (Figs. 6c, 6d, 6f, 6g-6k, $6 n-6 p) .{ }^{54}$ The band appearing at $1724 \mathrm{~cm}^{-1}$ is assigned to the stretching vibration mode of the carboxyl carbonyl group of TESP-SA (Figs. 6d$6 \mathrm{f}, 6 \mathrm{i}-6 \mathrm{k}, 6 \mathrm{l}-6 \mathrm{p})$. The absorption bands in region III (2800-3000 $\left.\mathrm{cm}^{-1}\right)$ are due to the -CHstretching vibrations of the methylene groups of cellulose and the propyl unit of the organotrialkoxysilanes GPTMS and TESP-SA.

The vibration modes appearing in region IV (3100-3500 $\mathrm{cm}^{-1}$ ) are assigned to $\mathrm{H}$-bonded $\mathrm{OH}$ stretching vibrations. The $\mathrm{OH}$ absorption bands appearing at wavelengths higher than $3400 \mathrm{~cm}^{-1}$ are assigned to intramolecular hydrogen bonds, whereas the bands observed at wavenumbers lower than $3400 \mathrm{~cm}^{-1}$ are due to intermolecular hydrogen bonds. ${ }^{55-57}$ Thus, the shoulder at 3440 $\mathrm{cm}^{-1}$ can be ascribed to the intramolecular hydrogen bonds, whereas the absorption bands at 3332 and $3283 \mathrm{~cm}^{-1}$ confirm the presence of intermolecular hydrogen bonds.

\section{Thermogravimetric analysis}

When polysaccharide-based materials, as well as other organic polymers, are subjected to thermal treatment at high temperatures, decomposition processes, such as depolymerisation, chain scission, oxidation, dehydration or decarboxylation, take place. ${ }^{58,59}$ Therefore, it is of high importance to study the thermal behavior of the organotrialkoxysilane/polysaccharide hybrid.

The decomposition curves (TG and DTG) of $\mathrm{RM}$, of the one-step treated and the three-step treated cotton samples are given in Figure 7. The curve of RM shows a moderate weight loss between $50-100{ }^{\circ} \mathrm{C}$, which is due to the evaporation of absorbed water. The peak temperatures where the highest rate of decomposition is obtained are almost the same.

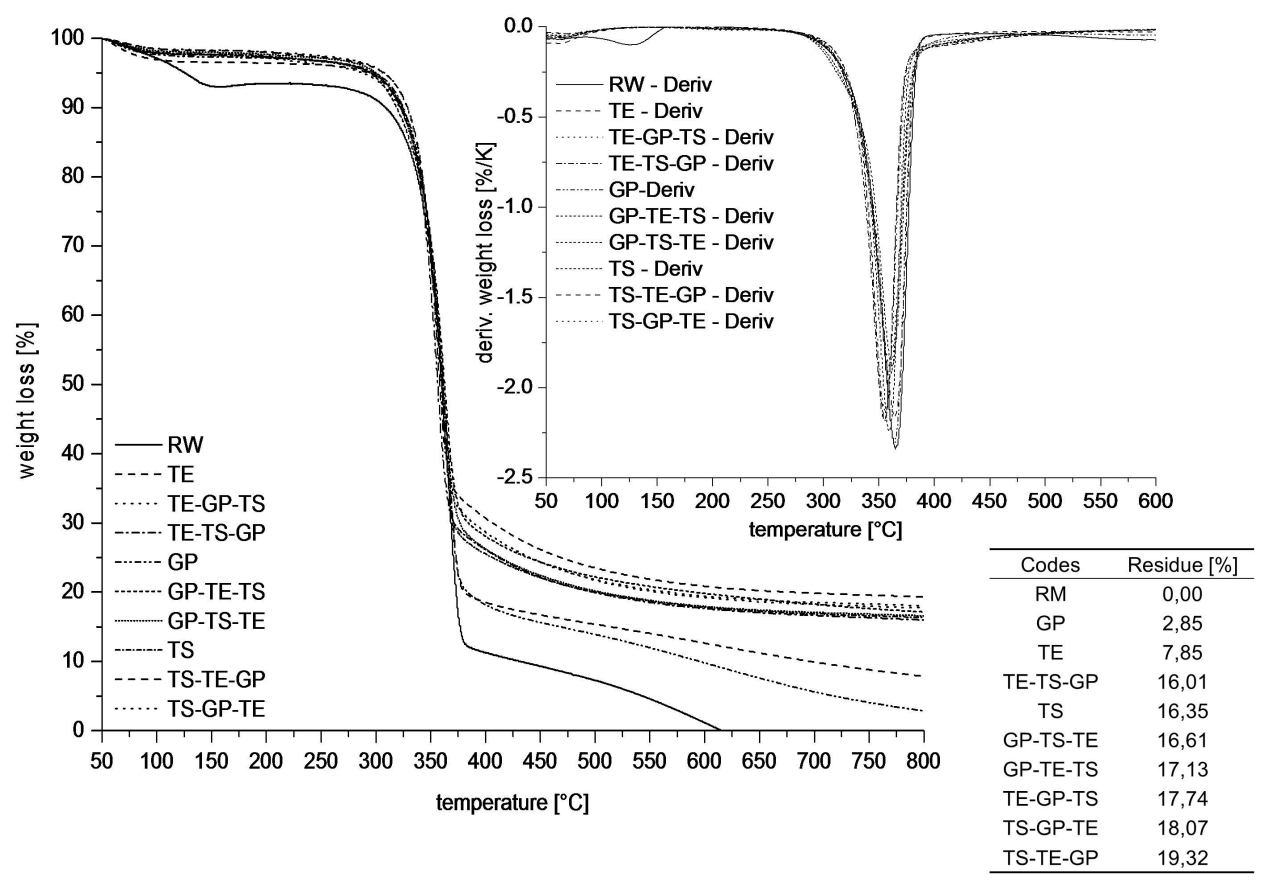

Figure 7: TGA curves and derivative TGA curves of the raw material (RM), the one-step-coated and three-step coated cotton material (table shows the corresponding residues) 


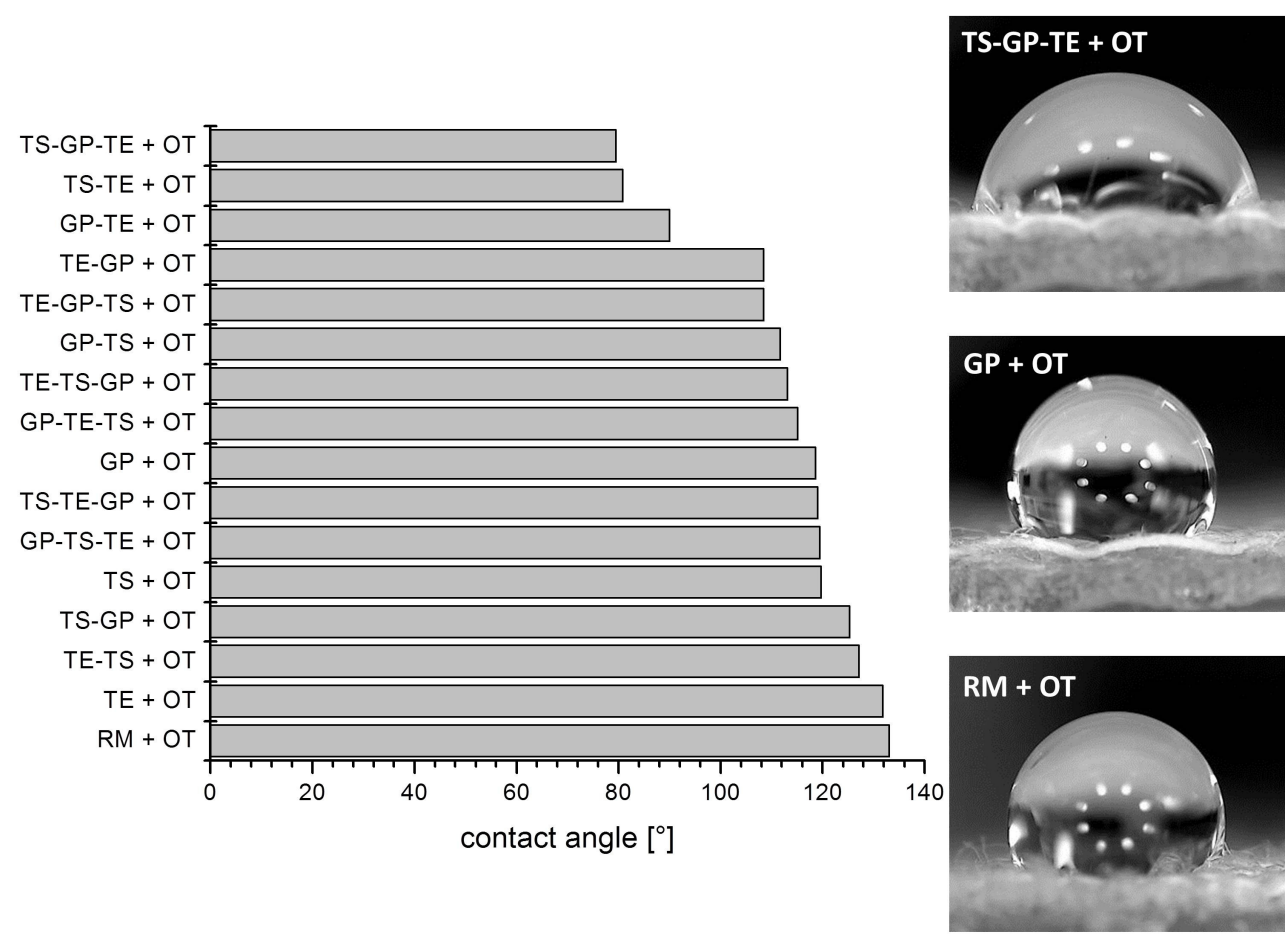

Figure 8: Contact angle values of all alkoxysilane-modified cotton samples coated with OTEOS

These findings are confirmed by the detailed information that can be extracted from the DTG curves. The table in Figure 7 indicates that the highest values for the residue are obtained for the three-step treated cotton samples. The highest values are obtained for TS-GP-TE and TS-TEGP.

\section{Incorporation of additives Modification with OTEOS}

Cellobiose, the constitutional repeating unit of the polysaccharide cellulose, is a hydrophilic material due to the six hydroxyl groups. To impart water-repellent properties to cotton material, the surface has to be modified with hydrophobic agents. For this purpose, hydrolyzed OTEOS is chemically attached to cotton material. Because of the hydrophobic character of the octyl group, OTEOS was hydrolyzed in an acidic ethanolic solution and applied to the corresponding cotton specimens by immersion. The as-prepared samples were dried at room temperature for $12 \mathrm{~h}$ and subsequently thermally treated at $150{ }^{\circ} \mathrm{C}$ for 15 min.

The contact angle was measured to evaluate the hydrophobic properties. The results are given in Figure 8. However, it has to be taken into consideration that the surface roughness increases the contact angle values, as described by the theories of Wenzel ${ }^{60}$ and Cassie/Baxter. ${ }^{61}$

The results demonstrate that the application of OTEOS to the alkoxysilane-treated cotton fabrics results in a reduction in the CA values, compared to the OTEOS-treated raw material. This observation can be explained by the fact that the treatment of the textile material with the alkoxysilanes causes an increase in the number of hydrophilic functional groups (hydroxyl groups and carboxyl groups).

\section{Modification with titanium dioxide}

Skin has to be protected from excessive UV radiation, since UV radiation (UVA $315-400 \mathrm{~nm}$, UVB 280-315 nm), being a component of the solar spectrum, has high skin damage potential. ${ }^{62,63}$ One measure is to incorporate sun protection agents, such as the white, inorganic pigments titanium dioxide and/or zinc oxide, into human clothing. We applied a titanium dioxidenanosol solution onto the cotton samples to impart UV blocking properties. The UPF values are presented in Figure 9.

The findings make it evident that the treatment with the alkoxysilanes moderately increases the UPF values, compared to the raw material. The incorporation of the titanium dioxide solution 
causes a significant improvement of the UV protection properties. The highest UPF values can be observed for the samples that have been treated with TESP-SA in the third step. This phenomenon may be due to the fact that the hydroxyl groups present on the surface of the titanium dioxide react via esterification with the carboxyl groups of the hydrolyzed TESP-SA, which is attached to the cotton material.

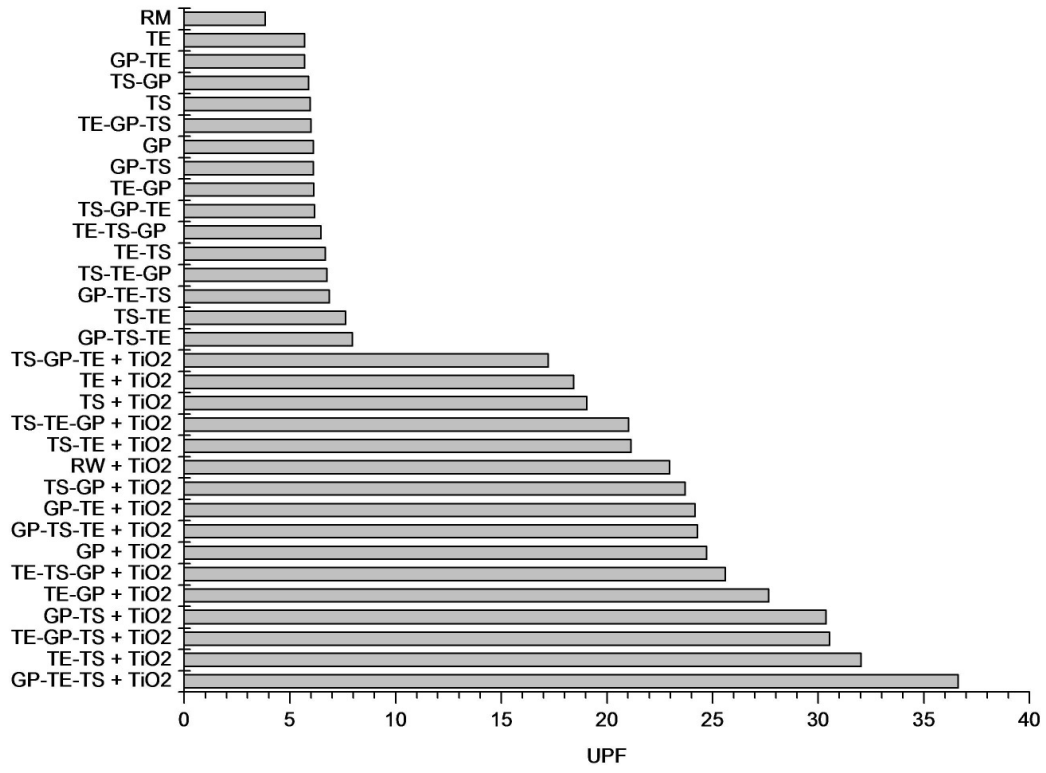

Figure 9: UPF values of the alkoxysilane-modified cotton samples treated with a TTP solution

\section{CONCLUSION}

Cotton-based material was chemically modified in a one-step process, two-step process and three-step process by means of nanosolsolutions containing various alkoxysilanes (TEOS, GPTMS, TESP-SA). The specimens were impregnated, dried and thermally treated at 140 ${ }^{\circ} \mathrm{C}$ for $20 \mathrm{~min}$. The DCRA characteristics were improved. As expected, TS values were reduced. The flexural rigidity reached the highest level when the specimens were modified in the threestep process. The samples impregnated three times showed the lowest abrasion resistance. The thermal treatment caused a decrease in the WI values. The modification of the alkoxysilanetreated samples with OTEOS resulted in a moderate reduction in the contact angle values. In addition, the as-prepared samples were treated with a titanium dioxide solution to improve the UV-blocking properties. A significant increase in the UPF values can be observed for the samples that were treated with the three alkoxysilane solutions, whereby the third impregnation was performed applying a TESP-SA containing solution.

ACKNOWLEDGEMENT: The authors gratefully acknowledge the FFG (Österreichische
Forschungsförderungsgesellschaft) for financial support of the project 846932 (Endowed Professorship in Advanced Manufacturing). The authors would like to thank the Testing Institute of the HTL Dornbirn (Austria) for allowing the use of their facilities.

\section{REFERENCES}

1 E. R. McCall and J. F. Jurgens, Text. Res. J., 21, 19 (1951), https://doi.org/10.1177/004051755102100105

2 J. W. Hearle, in "Ullmann's Fibers", vol. 2, WileyVCH, Weinheim, Germany, 2008

3 Y. F. Chow, A. Chan and C.-W. Kan, Text. Res. J., 82 , 1220

(2012),

https://doi.org/10.1177/0040517511429609

4 N. Bhat, A. Netravali, A. Gore, M. Sathianarayanan, G. Arolkar et al., Text. Res. J., 81, 1014 https://doi.org/10.1177/0040517510397574

(2011),

5 H. K. Rouette, in "Encyclopedia of Textile Finishing", Springer, 2014

6 B. Mahltig and T. Textor, "Nanosols and Textiles", World Scientific Publishing Co. Pte. Ltd., Singapore, 2008

7 C. J. Brinker and G. W. Scherer, "Sol-Gel Science: The Physics and Chemistry of Sol-Gel Processing", Academic Press, Boston, 1990

8 L. L. Hench and J. K. West, Chem. Rev., 90, 33 (1990), https://doi.org/10.1021/cr00099a003 
9 G. Kickelbick (ed.), "Hybrid Materials: Synthesis, Characterization, and Applications", Wiley-VCH, Weinheim, Germany, 2007

10 C. Colleoni, I. Donelli, G. Freddi, E. Guido, V. Migani et al., Surf. Coat. Technol., 235, 192 (2013), https://doi.org/10.1016/j.surfcoat.2013.07.033

11 B. Liu, Z. Wang and J. He, Mater. Lett., 67, 8 (2012), https://doi.org/10.1016/j.matlet.2011.09.017

${ }_{12}$ L. Lu, C. Hu, Y. Zhu, H. Zhang, R. Li et al., Cellulose, 25, 4223 (2018), https://doi.org/10.1007/s10570-018-1838-8

13 C. Schramm and A. Amann, Cellulose, 26, 4641 (2019), https://doi.org/10.1007/s10570-019-02391-3

14 C. Schramm and B. Rinderer, Cellulose, 22, 2811 (2015), https://doi.org/10.1007/s10570-015-0664-5

15 K. S. Huang, M. C. Hwang, J. S. Chen, S. J. Lin and S. P. Wang, J. Text. Inst., 98, 169 (2007), https://doi.org/10.1533/joti.2005.0300

16 K. S. Huang, Y. H. Nien, K. C. Hsiao and Y. S. Chang, J. Appl. Polym. Sci., 102, 4136 (2006), https://doi.org/10.1002/app.24246

17 G. Rosace, A. Castellano, V. Trovato, G. Iacono and G. Malucelli, Carbohyd. Polym., 196, 348 (2018), https://doi.org/10.1016/j.carbpol.2018.05.012

18 M. M. A. El-Hady, A. Farouk and S. Sharaf, Carbohyd. Polym., 92, $400 \quad$ (2013), https://doi.org/http://dx.doi.org/10.1016/j.carbpol.2012 .08 .085

19 J. Alongi and G. Malucelli, Polym. Degrad. Stabil., 98, 1428

(2013),

https://doi.org/http://dx.doi.org/10.1016/j.polymdegrad stab.2013.05.002

20 K. Sundaresan, A. Sivakumar, C. Vigneswaran and T. Ramachandran, J. Ind. Text., 41, 259 (2012), https://doi.org/10.1177/1528083711414962

21 C. H. Zheng, G. Q. Chen and Z. M. Qi, J. Appl. Polym. Sci., 122, $2090 \quad$ (2011), https://doi.org/10.1002/app.34289

${ }^{22}$ R. Paul, L. Bautista, M. De la Varga, J. M. Botet, E. Casals et al., Text. Res. J., 80, 454 (2010), https://doi.org/10.1177/0040517509342316

23 L. Cai, L. Dai, Y. Yuan, A. Liu and L. Zhanxiong, Appl. Surf. Sci., 371, $453 \quad$ (2016), https://doi.org/http://dx.doi.org/10.1016/j.apsusc.2016. 03.010

24 A. Boukhriss, D. Boyer, H. Hannache, J.-P. Roblin, R. Mahiou et al., Cellulose, 22, 1415 (2015), https://doi.org/10.1007/s10570-015-0565-7

25 T. Pipatchanchai and K. Srikulkit, J. Sol-Gel Sci. Technol., $\quad 44, \quad 119 \quad$ (2007), https://doi.org/10.1007/s10971-007-1609-8

26 C. Colleoni, M. R. Massafra and G. Rosace, Surf. Coat. Technol., 207, $79 \quad$ (2012), https://doi.org/10.1016/j.surfcoat.2012.06.003

27 N. Abidi, L. Cabrales and E. Hequet, ACS Appl. Mater. Interfaces, $\quad \mathbf{1}, 2141 \quad$ (2009), https://doi.org/10.1021/am900315t

${ }_{28}$ K. K. Gupta, M. Jassal and A. K. Agrawal, Indian J. Fibre Text. Res., 33, 443 (2008),
http://nopr.niscair.res.in/bitstream/123456789/2607/1/I JFTR\%2033\%284\%29\%20443-450.pdf

29 W. S. Tung and W. A. Daoud, J. Mater. Chem., 21, 7858 (2011), https://doi.org/10.1039/c0jm03856c

30 S. Hashemikia, N. Hemmatinejad, E. Ahmadi and M. Montazer, Mater. Sci. Eng. C, 59, 429 (2016), https://doi.org/https://doi.org/10.1016/j.msec.2015.09.0 92

31 M. Catauro, D. Verardi, D. Melisi, F. Belotti and P. Mustarelli, J. Appl. Biomater. Biomechan., 8, 42 (2010), https://doi.org/10.1177/228080001000800107

32 E. Pinho and G. Soares, J. Mater. Chem. B, 6, 1887 (2018), https://doi.org/10.1039/C8TB00052B

33 D. Klemencic, B. Tomsic, F. Kovac and B. Simoncic, Cellulose, 19, $1715 \quad$ (2012), https://doi.org/10.1007/s10570-012-9735-z

${ }_{34}$ P. Pisitsak and U. Ruktanonchai, Text. Res. J., 85, 949

(2015),

https://doi.org/10.1177/0040517514557310

35 B. Tomsic, B. Simoncic, B. Orel, L. Cerne, P. F. Tavcer et al., J. Sol-Gel Sci. Technol., 47, 44 (2008), https://doi.org/10.1007/s10971-008-1732-1

36 N. Chaudhury, R. Gupta and S. Gulia, Def. Sci. J., 57, 241 (2007), https://doi.org/10.14429/dsj.57.1765

37 C. Schramm, A. Kitzke and R. Tessadri, Cellulose Chem. Technol., 51, $273 \quad$ (2017), https://www.cellulosechemtechnol.ro/pdf/CCT34(2017)/p.273-282.pdf

38 C. Schramm and B. Rinderer, Fiber. Polym., 12, 226 (2011), https://doi.org/10.1007/s12221-011-0226$\mathrm{X}$

9 A. C. Aksit and N. Onar, J. Appl. Polym. Sci., 109, 97 (2008), https://doi.org/10.1002/app.27284.

40 A. F. Stalder, G. Kulik, D. Sage, L. Barbieri and P. Hoffmann, Colloids Surf., A, 286, 92 (2006), https://doi.org/10.1016/j.colsurfa.2006.03.008

41 T. Harifi and M. Montazer, Carbohyd. Polym., 88, 1125 https://doi.org/10.1016/j.carbpol.2012.02.017

42 M. Hewson, J. Soc. Dyer. Colour., 110, 140 (1994), https://doi.org/10.1111/j.1478-4408.1994.tb01628.x

43 V. A. Dehabadi, H. J. Buschmann and J. S. Gutmann, Text. Res. J., 83, 1974 (2013), https://doi.org/10.1177/0040517513483857

44 N. J. Abbott, Text. Res. J., 35, 197 (1965), https://doi.org/10.1177/004051756503500301

45 W. L. Xu and Y. Li, Text. Res. J., 70, 588 (2000), https://doi.org/10.1177/004051750007000705

46 A. Çay, S. Vassiliadis, M. Rangoussi and I. Tarakçioglu, Int. J. Cloth. Technol., 19, 18 (2007), https://doi.org/10.1108/09556220710717026

${ }^{47}$ K. Ahn, S. Zaccaron, N. S. Zwirchmayr, H. Hettegger, A. Hofinger et al., Cellulose, 26, 429 (2019), https://doi.org/10.1007/s10570-018-2200-x

48 J. Huang, Text. Res. J., 86, 325 (2016), https://doi.org/10.1177/0040517515588269

49 S. Pavlidou and R. Paul, in "Functional Finishes for Textiles", edited by R. Paul, Woodhead Publishing, 
2015 ,

pp.

http://dx.doi.org/10.1533/9780857098450.1.99

50 Y. Liu, Materials, 6, $299 \quad$ (2013), https://doi.org/10.3390/ma6010299

51 C. Chung, M. Lee and E. Choe, Carbohyd. Polym., 58, 417

(2004),

https://doi.org/10.1016/j.carbpol.2004.08.005

52 S. L. Warring, D. A. Beattie and A. J. McQuillan, Langmuir 32, $1568 \quad$ (2016) https://doi.org/10.1021/acs.langmuir.5b04506

53 Y. Huang, Z. Jiang and W. Schwieger, Chem. Mater., $\quad 11, \quad 1210 \quad$ (1999), https://doi.org/10.1021/cm980403m

54 D. Carboni, A. Pinna, L. Malfatti and P. Innocenzi, New J. Chem., 38, $1635 \quad$ (2014), https://doi.org/10.1039/c3nj01385e

55 T. Kondo and C. Sawatari, Polymer, 31, 293 (1996), https://doi.org/10.1016/0032-3861(96)82908-9

56 T. Kondo, Cellulose, 4, 281 (1997), https://doi.org/10.1023/A:1018448109214

57 Y. Hishikawa, S.-i. Inoue, J. Magoshi and T. Kondo, Biomacromolecules, 6, 2468 (2005), https://doi.org/10.1021/bm050032k
99, 58 D. Ciolacu and V. I. Popa, Cellulose Chem. Technol., $\quad 40, \quad 445 \quad$ (2006), https://www.cellulosechemtechnol.ro

59 A. M. A. Nada and M. L. Hassan, Polym. Degrad. Stabil., $\quad$ 67, $111 \quad$ (2000), https://doi.org/http://dx.doi.org/10.1016/S01413910(99)00100-7

60 R. N. Wenzel, Ind. Eng. Chem., 28, 988 (1936), https://doi.org/10.1021/ie50320a024

61 A. B. D. Cassie and S. Baxter, Trans. Faraday Soc., $\quad 40, \quad 546 \quad$ (1944), https://doi.org/10.1039/TF9444000546

62 R. Lucas, T. McMichael, W. Smith and B. Armstrong, "Solar Ultraviolet Radiation: Global burden of disease from solar ultraviolet radiation", WHO Environmental Burden of Disease Series, No 13, 1 (2006), https://apps.who.int/iris/bitstream/handle/10665/43505/ 9241594403_eng.pdf?sequence $=1$

63 T. Gambichler, K. L. Hatch, A. Avermaete, P. Altmeyer and K. Hoffmann, Photodermatol. Photoimmunol. Photomed., 18, 29 (2002), https://doi.org/10.1034/j.1600-0781.2002.180105.x 